\title{
Ethical Abuses in the Authorship of Scientific Papers
}

\author{
Marco Antonio A. Carneiro ${ }^{1,2}$, Silvia D. Cangussú ${ }^{2,3}$ \& G. Wilson Fernandes ${ }^{1}$
}

\begin{abstract}
${ }^{1}$ Ecologia Evolutiva \& Biodiversidade/DBG, Caixa Postal 486, ICB/ Universidade Federal de Minas Gerais, UFMG, 31270901 Belo Horizonte-MG ${ }^{2}$ Instituto de Ciências Exatas e Biológicas, Universidade Federal de Ouro Preto, 35400 000, Ouro Preto-MG.

${ }^{3}$ Neuro-imunopatologia Experimental/DPG, Instituto de Ciências Biológicas, Universidade Federal de Minas Gerais, 31270901, Belo Horizonte-MG.
\end{abstract}

\begin{abstract}
Ethical Abuses in the Authorship of Scientific Papers. Problems regarding the order of authorship of scientific papers have become more frequent and more abusive. These problems may have heightened due to the ever increasing pressure to "publish or perish" in the academic world, given that the publication of scientific articles has become the benchmark of success in a field with few job opportunities. This article reviews the abuses in the authorship of scientific papers. Different examples are given of the most common problems and recommendations are provided for authors and journal editors.
\end{abstract}

KEYWORDS. Authorship; co-authorship; publishing; science; writing papers.

RESUMO. Imposturas na Autoria de Artigos Científicos. Problemas relacionados a determinação de autoria de trabalhos científicos são freqüentes. Estes problemas vêm se agravando em decorrência da supervalorização do número de publicações no mundo acadêmico, uma vez que, a publicação de artigos científicos tornou-se uma referência de sucesso em um campo com poucas oportunidades de trabalho. Este artigo revê os abusos na autoria de artigos científicos. Diferentes exemplos são citados dos problemas mais comuns e recomendações básicas são feitas para autores e editores.

Even though several musicians may have at any one time collaborated on the composition of an opera there exist no records of these works being attributed to more than one author. The same can be said of great literature. For example, William Shakespeare left no works penned with collaborators (Griffith \& Babor 2000). In science, abuses related to the authorship of scientific studies occur with the exclusion or the inclusion of non meritorious researchers as authors.

During the last few decades, several authors have called attention to problems related to the abuses when determining the authorship of scientific studies (ICMJE 2006). These problems have been steadily rising due to the overestimation of the number of publications an author has (Bennett \& Taylor 2003). For example, in the United States most higher learning institutions consider the number of published papers a potential candidate for a faculty position has to be the main criterion for hiring, even when compared to a candidate with a comparatively superior ability to teach (Fleet et al. 2006). This "publish or perish" atmosphere has created a "race to publish" amongst researchers world wide (Brice \& Bligh 2004), resulting, many times, in studies of poor quality. In Brazil no similar data are available. Based on our collective experiences within public universities (Instituições Federais de Ensino Superior - IFES), however, the reality in Brazil is not much different from that in many other countries. In fact, the situation has worsened in the last few years due to lack of expansion and reduced renewal of faculty positions in the IFES.
Furthermore, the occurrence of dishonesty and far more serious unethical behavior has become more frequent, in one or more of the various steps necessary to publish a scientific paper. These practices bring into question the very value of science by placing at risk the trueness and reliability of the work of researchers. With the technologies available today, either for the rapid reproduction of papers or the dissemination of information at a global scale, this problem may worsen with the risk of introducing it as the standard to the next generation of researchers, that this improper conduct is in fact a rule of thumb. A different opinion is presented by Huth (1985) who believes that departures from correct conduct do not impede nor are they capable of slowing scientific development, and only rarely interfere with the efficiency of science. We believe that an ongoing debate regarding the authorship of scientific papers helps improve and stimulate the continuous process of learning and awareness, involving authors, editors, and the scientific community in general. Few studies in the entomological sciences deal with the theme of "authorship in scientific papers". Therefore, we hope to alert young Brazilian researchers to this theme. Furthermore, we offer a summary of the abuses committed during the process of defining the authorship of scientific papers and suggest some criteria, within the Brazilian scenario, to inhibit them. In order to avoid judicial implications and personal disputes we will use 'hypothetical' situations. 
Why publish? The publication of a scientific paper contributes in various ways to increasing knowledge and is the goal of any researcher. In publishing a paper the researcher advertises his or her research, communicates ideas, allowing their experiment to be replicated and tested by their colleagues. The researcher also guarantees his or her originality and their copyright by authorship. Because papers are fundamental to the development of science, the quantity of scientific publications is used as a criterion in hiring faculty, promotions in mid career, awarding funding, and scholarships for students, in addition to the advancement of an individual researcher and international peer recognition (Bennett \& Taylor 2003). The quality of publications has also been adopted as a criterion in the last few years. One of the methods recently used to evaluate the quality of papers is to consider the impact factor of the periodical in which the paper is published (see Coelho et al. 2003). According to Griffith \& Babor (2000) a scientific publication is the 'coin of the realm in the academic world', but at times this 'wealth' may have been acquired at the expense of conflicts between professionals, negatively affecting the motivation of researchers and their relationships at work.

Stages in the Elaboration of a Scientific Paper. The elaboration of a scientific paper undergoes several stages before publication (Fig. 1). Each subsequent stage is extremely dependent on the previous stage and any error in one or more of these initial stages can lead to the termination of the entire process. Without going into the epistemological considerations surrounding scientific development (for an introduction see Martins \& Mari 2002; Pickett et al. 1994), we identified seven fundamental stages.

The first stage is the formulation of a question or a hypothesis to be tested. This is a fundamental step because any good science begins with a good question, and various authors have already warned of the importance of formulating a good question (Lawton 1992). According to Albert Einstein "The formulation of a problem is often more essential than its solution...." After formulating a good question next comes the experimental design, or rather, how will the question be answered? A good experimental design is crucial in scientific development (Quinn \& Keough 2002), and it is not trivial to say that many good questions remain unanswered, waiting to be answered due to limited budgets, logistics, or techniques. With a question in hand and a way to test it, the next step is to execute the method (experiment or the collection of field data). Here we highlight that any good science should always have a good empirical base (Price 1991). With the data available and the adequate tools to analyze them, we continue on to the next stage of data analysis. Again, it is the intellectual work or the "novel idea" which makes the difference. An important characteristic of this phase is that it returns to the formulation of new hypothesis and experimental designs, establishing a feedback system.

The next stage is the writing of the scientific paper. This part is different from the rest because a large majority of the scientific community will only have access to the published paper and will have to judge the entire process based on the quality of the paper. A clear and concise paper, which correctly uses scientific jargon related to its particular area of research (Fauth et al. 1996), is true to reality (including recognizing its failures and limitations), and is strongly supported by scientific literature is the climax of the entire scientific process. With the paper finished, the authors submit it for publication in a magazine or journal of their choice. The submission may at first glance appear to be a simple part of the elaboration of a paper. Nevertheless, careful consideration should be given to this step because different journals emphasize different scientific themes. In order to choose the most appropriate journal to publish your study, both the line of research published by the journal and the profile of the researchers which comprise the editorial board must be considered. Fundamental in this decision is the proficiency and help of a student's advisor. Lastly, an analysis of the paper by the reviewers of the journal is conducted. Reviewers are chosen that specialize in the specific area which pertains to the contents of the paper. Papers sent out for review are returned with comments from the reviewers and a decision by the editor as to the suitability for publication in the journal. The editor frequently requests major or minor modifications, based on the reviewers' comments, and states that the paper "may" be publishable after the modifications are made. Final acceptance depends on an adequate revision within the timeframe given by the editor. Furthermore, a detailed letter to the Editor explaining all of the changes made in the revised version must accompany the revised paper. Some papers are returned with the recommendation that the paper be completely rewritten and submitted as a new paper, while others are completely rejected. This entire process may take as little as 2 months or as long as 1 year.

Defining Authorship, First and Multiple Authors. An important characteristic of the writing stage is to define, in complete accordance with all the participants, the first author and the order of the other authors. Authorship should be defined by merit (sensu stricto) and by actual participation. In our experience, over $90 \%$ of the time this decision has already been made during the initial stages of the process. According to the recommendations of the International Committee of Medical Journal Editors (ICMJE 2006), in order to be an author the researcher should satisfy the following criteria: 1) contribute substantially in the conception and design of a study, and or acquisition and /or interpretation of the data; 2) participate in the elaboration or make a fundamental critical revision of the intellectual content of the manuscript; 3) and authorize the final version that will be sent to the journal for review.

The first author or main author should be the person that worked the most during the process of elaboration of the paper. Even if he or she did not have mastery of all the techniques or even participated in the entire process of data collection and/ or data analysis, this person is recognized as the person who fully understands the entire content and conceptual framework 
of the paper (Montenegro \& Alves 1997). For example, it is common for a professor to do all of the statistical analysis or translation of a text to English, abilities not yet completely mastered by many students. In this context, many advisors maintain the names of their students as the main author; however, sometimes advisors place themselves as first author inappropriately, while their students, who have done most of the work, are placed as co-authors (Hammersley 2001). Sometimes it is justifiable that the advisor be placed as the main author. For example, when a student after finishing his studies decides not to continue his work or does not have an interest in publishing, it is appropriate for the advisor to be first author because he or she must do all the work for publishing the research. Another way of resolving the problem of authorship has been to adopt a system where the first author rotates amongst members of a research group, thereby maximizing the collective progress of the careers of all of the researchers involved. However this "rotation" method continues to do harm to the definition of what a main author means (Hammersley 2001). We agree with the practice of advisors maintaining their students as main authors in papers that result from undergraduate theses as a means of giving credit and stimulus to new researchers (who will in the future follow this example). In truth, this is already standard practice in Brazil, given that, in project evaluations conducted by the Ecology and Limnology committee of CNPq (G. W. Fernandes, pers. comm..) and by the Ecology and Environment committee of CAPES (F. R. Scarano, pers. comm.), the order in which authors appear is not considered as a criteria when attributing points during evaluations, as it is assumed that the last author is generally the advisor. In a very few cases of multi-authored article, the advisor places himself as the second or third author as an indication of a larger involvement with the ideas and work. Otherwise, we argue that in articles with more than three authors it is difficult to assign to one in the group the amount of work done and that if one considers that the last author is the advisor, it should be the place to be taken by them.

A fundamental characteristic of the main author is that he or she should be able to answer publicly for the scientific content of the work conducted. It is understood that "to answer publicly for the scientific content of a study" is, when the author is questioned he or she should be capable of defending the ideas and conclusions of the study, and consequently, of all the stages in the elaboration process of the paper. Although, we note here that all the authors can and should be civilly and criminally responsible for whatever problem should arise from the publication of the paper. It is important to remember that the editorial board is free of any and all responsibility as soon as they advise the authors that the contents of the paper are of their responsibility (see above).

The other authors, co-authors or collaborators are naturally advisors or other people that effectively participate in the research group, in one or more stages of the process of preparing the paper. Laboratory colleagues or college level technicians that participate extensively in collecting data and sorting material in the laboratory or in the field should, obligatorily, participate as co-authors. Some authors consider the 'simple' collecting of data not worthy of attaining coauthorship, because many times the collector is not capable of defending the contents of the published paper (Montenegro \& Alves 1997). Although this is a cause for concern, we recommend that research groups attempt to insert these individuals (undergraduate students or graduated lab tech) into other parts of the process in order to avoid them becoming "slave" field or laboratory data collectors, or rather, a person that participates in the study yet does not have his name included in the list of authors.

In most scientific disciplines studies featuring only one author are quite rare and there is a tendency towards papers with multiple authors. This occurs because of a strong pressure on researchers to increase their number of publications. Multiple authorship occurs for a series of practical reasons and attitudes, many of which are legitimate and in line with the natural trajectory of the development of knowledge. These include: 1) the increase in the specialization of knowledge and of the use of ever more sophisticated techniques (Zollikofer $e t$ al. 2002); and 2) the tendency to value multidisciplinary studies, as well as studies on a large or inter-institutional scale that necessarily require a large sampling effort (e.g. Brunet $e t$ al. 2001).

According to Hilmer \& Hilmer (2005), the quality of publications from American universities within the agricultural economics sector has a great impact on the earnings of its teaching staff. Furthermore, the financial windfall is greater when papers are published by a single author. They also found that there was no additional financial gain in publishing papers with multiple authors in which their names were not in alphabetical order.

Whose responsibility is it? One of the main pernicious consequences of papers with multiple authors is the dilution of responsibility (Bennett \& Taylor 2003), which ultimately may result in lower quality of the paper. Inevitably, one can find studies in which neither the first author nor the other collaborators are capable of explaining the entire content of the paper, always attributing the more obscure parts of the paper to another author. Many times due to disagreements between researchers after the work is finished, one of them might, erroneously, believe that he or she is the owner of the data and decides not to publish them thereby forgetting the duty to divulge their results, which many times has been financed with public funds! Also, the name of a member of the group (see below, ghost author) may be wrongly removed from the by-line and none of the other authors know whose responsibility it was. In this case, are all the authors of the paper responsible for the removal or only the author that sent the paper to the journal?

Irregularities in Authorship and Publication. According to Bennett \& Taylor (2003) there are several irregularities in scientific publications related to authorship (Fig. 1). The Guest 
author is one whose name is included in the list of authors without having fulfilled the requirements stated above. Simply because he or she lent equipment or biological material, for example, insects, cells, or strains in order to carry out an experiment (Gift author), does not give them the authorship rights. The Pressured author (a specific case of the Guest author) is one who has their name wrongly included in a paper because he or she is the head of the laboratory where the study was conducted. Being the head or 'guru' of a group of researchers, their subordinates feel pressured to include their "boss" because of his or her position in the hierarchy and the overall dominating figure that an advisor represents. Another aspect that motivates the addition of the "boss" is that depending on the boss's reputation in the academic world the paper may have a greater chance of being published. This is a very common irregularity and undoubtedly will increase with the current formation of large groups of collaborators poised to answer the demand for evermore papers requested by funding agencies. The ghost author is a person who has his or her name removed from the list of authors even though he or she contributed significantly to the process of elaboration of the paper. We feel that this is the worst type of irregularity because it seriously affects the authorship rights of the researcher. For example, due to a personal misunderstanding, between advisor and advisee, one removes the name of the other, many times citing that this was justified because the studies continued, and the publication lacking the authors name is the result of this further research. Here we call attention to the fact that even when there was continuity in the research, the previous authors should not lose their right to authorship.

In addition to these authorship irregularities Bennett \& Taylor (2003) recognize two other types of irregularities in connection to the publication of scientific papers: the publication of duplicate papers (often in two languages) and the divided publication. The duplicated publication refers to the publication of the same paper in various journals without any significant modification which would warrant another publication. This form of self-plagiarism is one of the most serious irregularities in scientific publications and should be recognized and penalized as such. It is especially important that young researchers and graduate students understand that this is not an acceptable form of academic behavior. The same results can be presented only one time. Some of the same data may be used in other publications, if they address a different question, but under no circumstances it is acceptable to publish the same paper in different journals, even if the language is different. The divided publication refers to the fragmentation of data in an attempt to increase the number of publications. In both cases there is an unnecessary increase in the volume of information without any guarantee of its improvement (Bennett \& Taylor 2003). The limitation of space and the ever increasing necessity by editors for more concise papers stimulates (but does not necessarily justify) the divided publication (Brice \& Bligh 2004). Divided and duplicated publications also are "encouraged" by research institutions and funding agencies which demand evermore publications

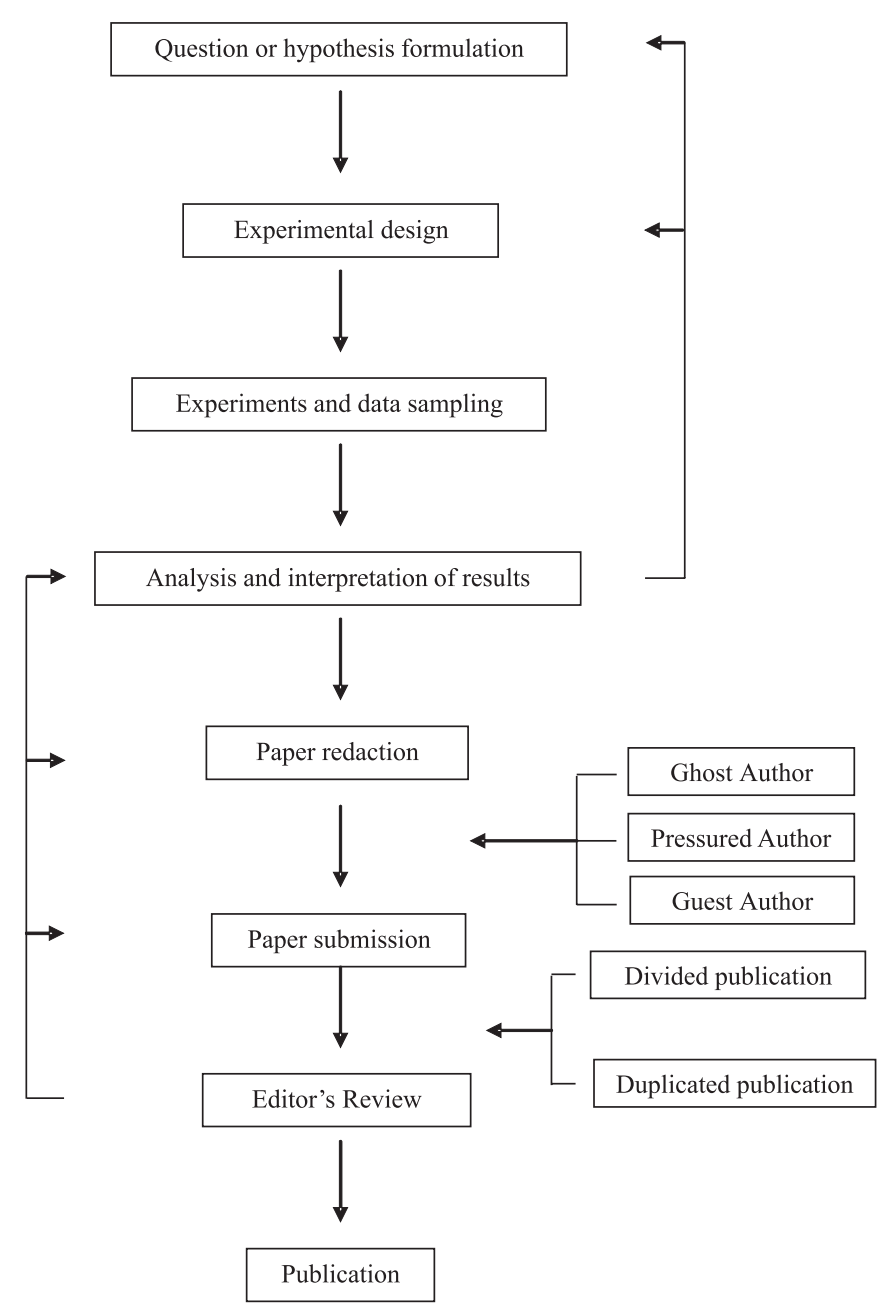

Fig. 1. Stages in preparing a scientific paper up to its publication. In the elaboration of scientific papers, two stages, "analysis and interpretation of results" and "peer reviewing" influence other phases of the paper preparation. The figure also shows the problems related to authorship (ghost author, pressured author and guest author) or publication (duplicated and divided)

in a shorter time span from researchers (Brice \& Bligh 2004; Hilmer \& Hilmer 2005).

Giving Credit to Institutions and Funding Agencies. Scientific papers are published in journals or periodicals managed by societies or scientific institutions which possess an editorial board composed of high caliber researchers, indicated or otherwise selected by their peers. Scientific journals offer in their "instructions to authors" section a warning that the contents of the paper being submitted are the complete responsibility of its authors and that the journal will only accept original work. Almost as a rule, funding agencies advise, explicitly, in their proposal applications that the researcher should cite the origin of the funding used to subsidize their work. Similarly, institutions or graduate programs which employ researchers request that the name of the institution to be listed together with the author. All of 
these requirements to give credit, be them from institutions or funding agencies, occur because of the renowned value of the role of the scientific publication as a "currency" in the academic world. At times, due to moving from one institution to another, a researcher may arbitrarily change the name of the institution at which he conducted his original research failing to give proper credit to the institution where the research was conducted. This act, which many times is justified as a simple "mental lapse" is a harmful attitude towards the original institution.

Recommendations. Based on what we have presented here, we now highlight a few suggestions towards establishing authorship. It is not our intention to stipulate here a list of actions, or define a handbook of proper conduct. We only hope to call attention to some points repeatedly cited in the literature which may help minimize irregularities with respect to authorship. They are: 1) The first author should always do the majority of the work (even if he or she is a student) followed by the other authors in decreasing order of involvement in the work; 2) Papers resulting from undergraduate monographs, dissertations, or theses should always have the student as the first author (except in specific cases as described above); 3) The names of the authors should be placed in alphabetical order of the last name, in papers with more than three authors, following the third author; 4) Journals ought to require that authors sign a pledge stating that they know the contents of the paper being submitted, that they were the only authors, and that they authorized sending the final version for review.

In summary, we believe that a permanent debate concerning the authorship of scientific papers will contribute to the improvement of scientific work by stimulating the learning process and awareness of the new generation of researchers. We suggest the establishment of a permanent forum comprised of editors from scientific journals edited in Brazil with the objective of maintaining an active debate concerning authorship in scientific papers. Guaranteeing the constant improvement and investing evermore in improving the formation of new researchers is fundamental to the development of Brazilian science. Paraphrasing John Lawton (1992): 'We should never holdback our young researchers because they are the fountain of innovation.'

Acknowledgements. We would like to thank F.A.O. Silveira, J.S. Almeida-Cortez, Y. Oki, and especially K. Stoner and F.R. Scarano for their helpful comments and criticisms on the manuscript. We also thank the editor of the Revista Brasileira de Entomologia for the opportunity. We also acknowledge scholarships and grants provided by CNPq, CAPES and FAPEMIG.

\section{REFERENCES}

Bennett, D. M. \& D. M. Taylor. 2003. Unethical practices in authorship of scientific papers. Emergency Medicine 15: 263-270.

Brice, J. \& J. Bligh. 2004. Author misconducts: not just the editor's responsibility. Medical Education 39: 83-89.

Brunet, M.; F. Guy; D. Pilbean; H. T. Mackaye; A. Likius; D. Ahounta; A. Beauvilain; C. Blondel; H. Bocherens; J. R. Boisserie; L. D. Bonis; Y. Coppens; J. Dejax; C. Denys; P. Duringer; V. Eisenmann; G. Fanone; P. Fronty; D. Geraads; T. Lehmann; F. Lihoreau; A. Louchart; A. Mahamat; G. Merceron; G. Mouchelin; O. Otero; P. P. Campomanes; M. P. De Leon; J. C. Rage; M. Sapanet; M. Schuster; J. Sudre; P. Tassy; X. Valentin; P. Vignaud; L. Viriot; A. Zazzo \& C. Zollikofer. 2002. A new hominid from the upper Miocene of Chad, central Africa. Nature 418: 145-801.

Coelho, P. M. Z.; C. M. F. Antunes; H. M. A. Costa; E. G. Kroon; M. C. S. Lima \& P. M. Linardi. 2003. The use and misuse of the impact factor as a parameter for evaluation of scientific publication quality: a proposal to rationale its application. Brazilian Journal of Medical and Biological Research 36: 1605-1612.

Fauth, J. E.; J. Bernardo; M. Camara; W. J. Resetarits; J. V. Buskirk \& S. A. McCollum. 1996. Simplifying the jargon of community ecology: a conceptual approach. American Naturalist 147: 282286.

Fleet, C. M.; M. F. N. Rosser; R. A. Zufall; M. C. Pratt; T. S. Feldman \& A. P. Lemons. 2006. Hiring criteria in biology departments of academic institutions. BioScience 56: 430-436.

Griffith, E. \& T. F. Babor. 2000. Shakespeare and the meaning of authorship. Addiction 95: 1317-1318.

Hammersley, R. 2001. Letters to the editor. Addiction 96: 507-517.

Hilmer, C. E. \& M. J. Hilmer. 2005. How do journal quality, coauthorship, and author order affect agricultural economist's salaries? American Journal of Agricultural Economics 87: 509-523.

Huth, E. J. 1985. Irresponsible authorship and wasteful publication. Annals of International Medicine 104: 257-259.

International Committee of Medical Journal Editors. Uniform requirements for manuscripts submitted to biomedical journals. Available at http://www.icmje.org/index. Accessed in June, 2006.

Lawton, J. H. 1992. (Modest) advice for graduate students. Oikos 65: 361-362.

Martins, R. P. \& H. Mari (eds.). 2002. Universos do Conhecimento. Belo Horizonte, Editora da Faculdade de Letras da UFMG, 246 p.

Montenegro, M. R. \& V. A. F. Alves. 1997. Critérios de autoria e coautoria em trabalhos científicos. Acta Botanica Brasilica 11: $273-276$.

Pickett, S. T. A.; J. Kolasa \& C. G. Jones. 1994. Ecological Understanding: the nature of theory and theory of nature. New York, Academic Press, xiii+206 p.

Price, P. W. 1991. Darwinian methodology and the theory of insect herbivore population dynamics. Annals of the Entomological Society American 84: 465-473.

Quinn, G. P. \& M. J. Keough. 2002. Experimental Design and Data Analysis for Biologists. Cambridge, Cambridge University Press, $\mathrm{xvii}+537 \mathrm{p}$.

Zollikofer, C. P. E.; M. P. De Leon; D. E. Lieberman; F. Guy; D. Pilbean; A. Likius; H. T. Mackaye; P. Vignaud \& M. Brunet. 2002. Virtual reconstruction of Sahelanthropus tchadensis. Nature 434: $755-759$. 